$$
D \circ E / P C / \begin{aligned}
& \mathrm{DOE} / \mathrm{PC} / 90312-\mathrm{T} 4 \\
& \mathrm{DE} 92004864
\end{aligned}
$$

\title{
HOT GAS DESULFURIZATION WITH SORBENTS \\ CONTAINING OXIDES OF ZINC, IRON, VANADIUM AND COPPER
}

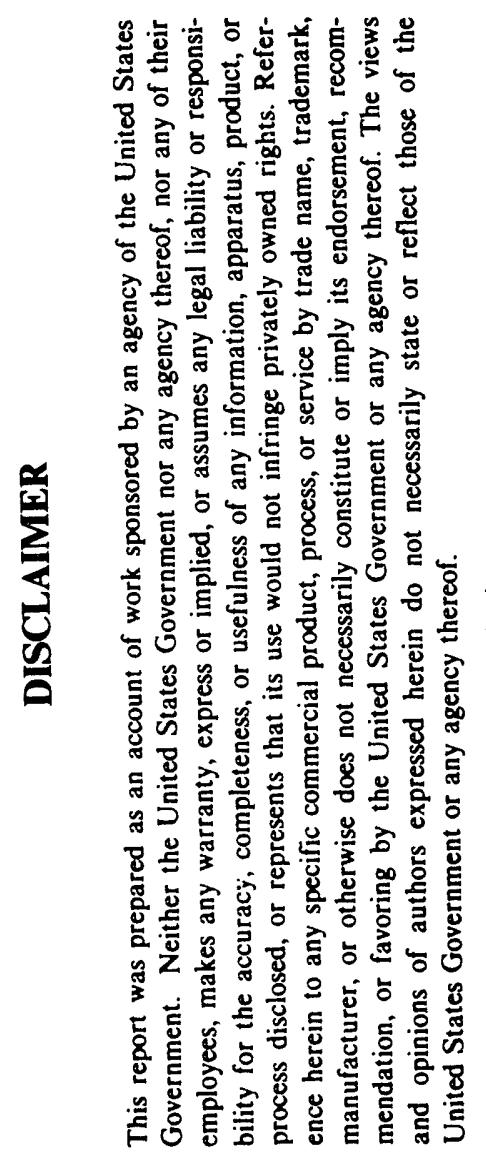

GRANT NUMBER: DE-FG22-90PC90312

START DATE: October 1, 1990

EXPECTED COMPLETION DATE: August 31, 1992

PRINCIPAL INVESTIGATOR: Ates Akyurtlu
CO-INVESTIGATOR: Jale F. Akyurtlu

\author{
Department of Engineering \\ Hampton University \\ Hampton, VA 23668
}

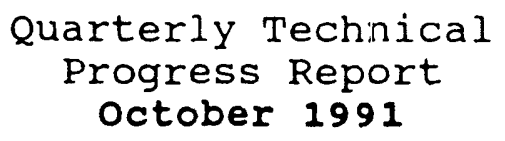




\section{Nov 15}

\section{ABSTRACT}

The main objective of this research is to evaluate the desulfurization performance of novel sorbents consisting of different combinations of zinc, iron, vanadium and copper oxides; and to develop a sorbent which can reduce $\mathrm{H}_{2} \mathrm{~S}$ levels to less than 1 ppmv, which can stabilize zinc, making operations above $650^{\circ} \mathrm{C}$ possible, and which can produce economically recoverable amounts of elemental sulfur during regeneration. This objective will be accomplished by evaluating the sorbent performance using fixed-bed and TGA experiments supported by sorbent characterization at various reaction extents.

The work done in the fourth quarter can be summarized as follows:

- Calibration of the gas chromatograph for low and high $\mathrm{H}_{2} \mathrm{~S}$ and $\mathrm{SO}_{2}$ is completed.

- The determination of surface areas and densities of the promoted sorbents is completed.

- Preliminary screening of the promoted sorbents in the packed bed reactor has started.

The results of this work will be presented at the 1992 AIChE Spring National Meeting. 


\section{WORR DONE}

sorbent characterization: In the fourth quarter the measurement of the surface areas and the helium densities of promoted sorbents was completed. Appendix A shows the compositions and the physical characteristics of the promoted sorbents. These sorbents are prepared by impregnating the $\mathrm{zinc}$ ferrite sorbents supplied by United Catalysts, with vanadiur: pentoxide using the incipient wetness technique and then calcining the dried sorbents in air. The last group of numbers in the catalyst name indicate the calcination temperature. Table A.I shows that calcination at high temperature $\left(750^{\circ} \mathrm{C}\right)$ results in a significant decrease in the surface area of the sorbent.

Packed Bed Reactor Experiments: Preliminary screening of the promoted sorbents in the packed bed reactor has begun. The procedures for sulfidation and regeneration experiments are given in Appendix B, and Appendix C contains the breakthrough curves for two sorbents. Both sorbents show pre-breakthrough $\mathrm{H}_{2} \mathrm{~S}$ concentrations appreciably below $1 \mathrm{ppm}$. In fact, no $\mathrm{H}_{2} \mathrm{~S}$ peaks were visible in chromatograms obtained with an FPD detector. A high breakthrough conversion, 65\%, was obtained with the sorbent calcined at the lower temperature, $\epsilon$ ? ${ }^{\circ} \mathrm{C}$ while the sorbent calcined at a higher temperature gave a breakthrough conversion of about $3 \%$. This is due to the substantially lower surface area of the latter. This sorbent was then subjected to two sulfidation-regeneration cycles. From the breakthrough curves it appears that this sorbent retains its sulfur capture capacity and sulfur removal efficiency through two cycles. In fact, the breakthtough conversion for the second cycle is even slightly higher than that for the first cycle.

During these preliminary tests there was no elemental sulfur formation. With both sorbents a large amount of $\mathrm{H}_{2} \mathrm{~S}$ chemisorption was observed. 
Presentations and Publications: The preliminary results from this work will be presented at the 1992 AIChE spring National Meeting in New orleans. The abstract is accepted for presentation in the session on "Contaminant Removal from Gas". 


\section{FUTURE PLANS}

In the next quarter:

1. Preliminary screening of the promoted sorbents in the packed bed reactor will be continued.

2. The determination of pore volumes and pore size distributions of the promoted sorbents will be completed. 


\section{APPENDIX A}

Table 1. Sorbent Characteristics

\begin{tabular}{||c|c|c|c|}
\hline Sorbent & $\begin{array}{c}\text { Zn:Fe:V Ratio } \\
\text { (mass) }\end{array}$ & $\begin{array}{c}\text { Helium Density } \\
\left(\mathrm{g} / \mathrm{cm}^{3}\right)\end{array}$ & $\begin{array}{c}\text { Surface Area } \\
\left(\mathrm{m}^{2} / \mathrm{g}\right)\end{array}$ \\
\hline ZF-V01-600 & $25.6: 41.9: 0.84$ & 5.384 & 2.854 \\
\hline ZF-V01-750 & $26.2: 42.1: 0.77$ & 5.470 & 1.032 \\
\hline ZF-V03-600 & $23.9: 40.5: 2.90$ & 5.357 & 2.828 \\
\hline ZF-V03-750 & $24.1: 39.4: 2.56$ & 5.240 & 1.006 \\
\hline ZF-V04.8-600 & $23.1: 37.8: 3.99$ & 5.149 & 2.960 \\
\hline ZF-V04.8-750 & $25.5: 40.7: 3.96$ & 5.219 & 0.8271 \\
\hline ZF-V15-600 & & 4.514 & 1.934 \\
\hline ZF-V15-750 & & 4.537 & 0.4879 \\
\hline
\end{tabular}




\section{APPENDIX B}

\section{Procedure for sulfidation Runs}

1 - Open reactor exhaust valve.

2- Turn on auxilliary nitrogen to reactor.

3- Turn reactor heater on.

4- Turn the selector valve on the nitrogen line to water saturator and turn the saturator heater on.

5- Turn line heaters on.

6- Turn the first selector valve on reactor feed line to exhaust and adjust feed composition.

7- Turn the second selector valve on the reactor feed Iine to reactor bottom.

8- Turn the gas chromatograph TCD on and ignite the FPD flame. Prepare data aquisition system.

9- Inject feed gas sample to gas chromatograph.

10- When the reactor reaches the desired temperature turn the auxilliary nitrogen off and turn the selector valve on the reactor feed line to reactor. Start the stop-watch.

11- Take gas samples from reactor exit and inject to gas chromatograph.

12- After the breakthrough curve is obtained turn the reactor heater off and turn the feed selector valve to exhaust.

13- Turn off all line heaters, water saturator heater, and the gas feed.

\section{Procedure for Regeneration Runs}

1- Fill the iodine bottle with fresh solution.

2- Turn the first feed selector valve to exhaust and the second selector valve to reactor top.

3- Turn nitrogen on and adjust its flow rate.

4- Turn the line heaters on. 
5- Turn the gas chromatograph TCD on and ignite the FPD flame. Prepare data aquisition system.

6.- Turn the reactor heater on and turn the selector valve on the feed line to reactor.

7- Take gas samples from the reactor exit and inject to gas chromatograph.

8- Continue until no hydrogen sulfide is observed in the gas samples.

9- Take a sample from the iodine solution and titrate to find the amount of chemisorbed hydrogen sulfide.

10- Turn oxygen on and adjust regeneration gas composition.

11- If a wet run is desired, turn the selector valve on the nitrogen line to water saturator and turn the saturator heater on.

12- Take samples from the reactor exit and inject to gas chromatograph.

13- Continue until no more sulfur dioxide is observed.

14- Cut off oxygen and check if any sulfur dioxide is observed in the regeneration off-gas indicating the presence of sulfates.

15- Take a sample from the iodine solution and titrate to find the sulfur capacity of the sorbent.

16- Turn off the reactor heater and the line heaters.

17- Turn the selector valve on the feed line to exhaust and turn off the gases. 


\section{APPENDIX C}

Figure 1. Breakthrough curves for sulfidation at $600^{\circ} \mathrm{C}$. Sulfidation gas composition: $\mathrm{H}_{2} 21 \%, \mathrm{H}_{2} \mathrm{~S} 1.1 \%$, balance $\mathrm{N}_{2}$.
a) For sorbent $\mathrm{ZF}-\mathrm{VO} 1-600$
b) For sorbent $\mathrm{ZF}-\mathrm{V} 01-750$
- Cycle 1
+ Cycle 2 

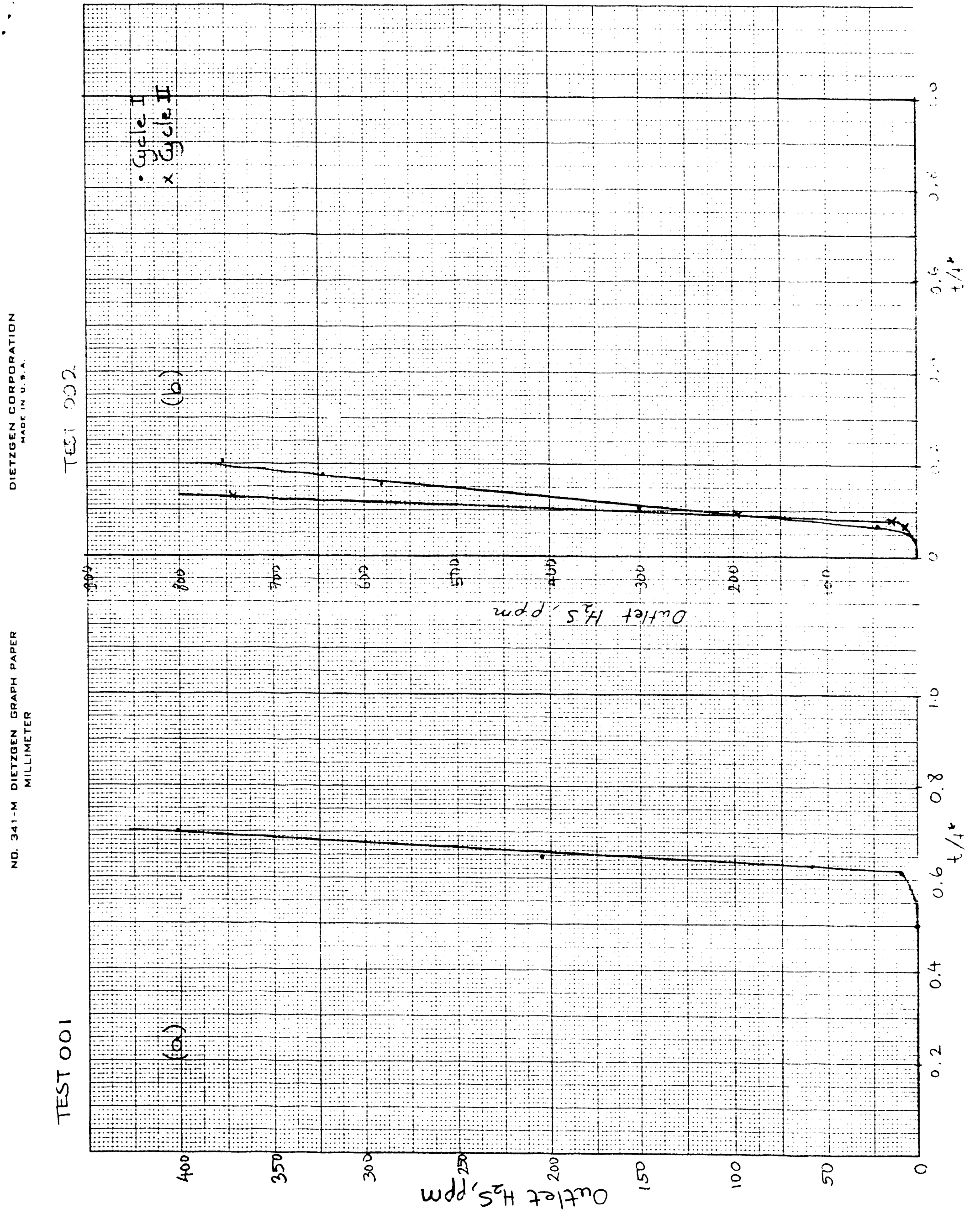

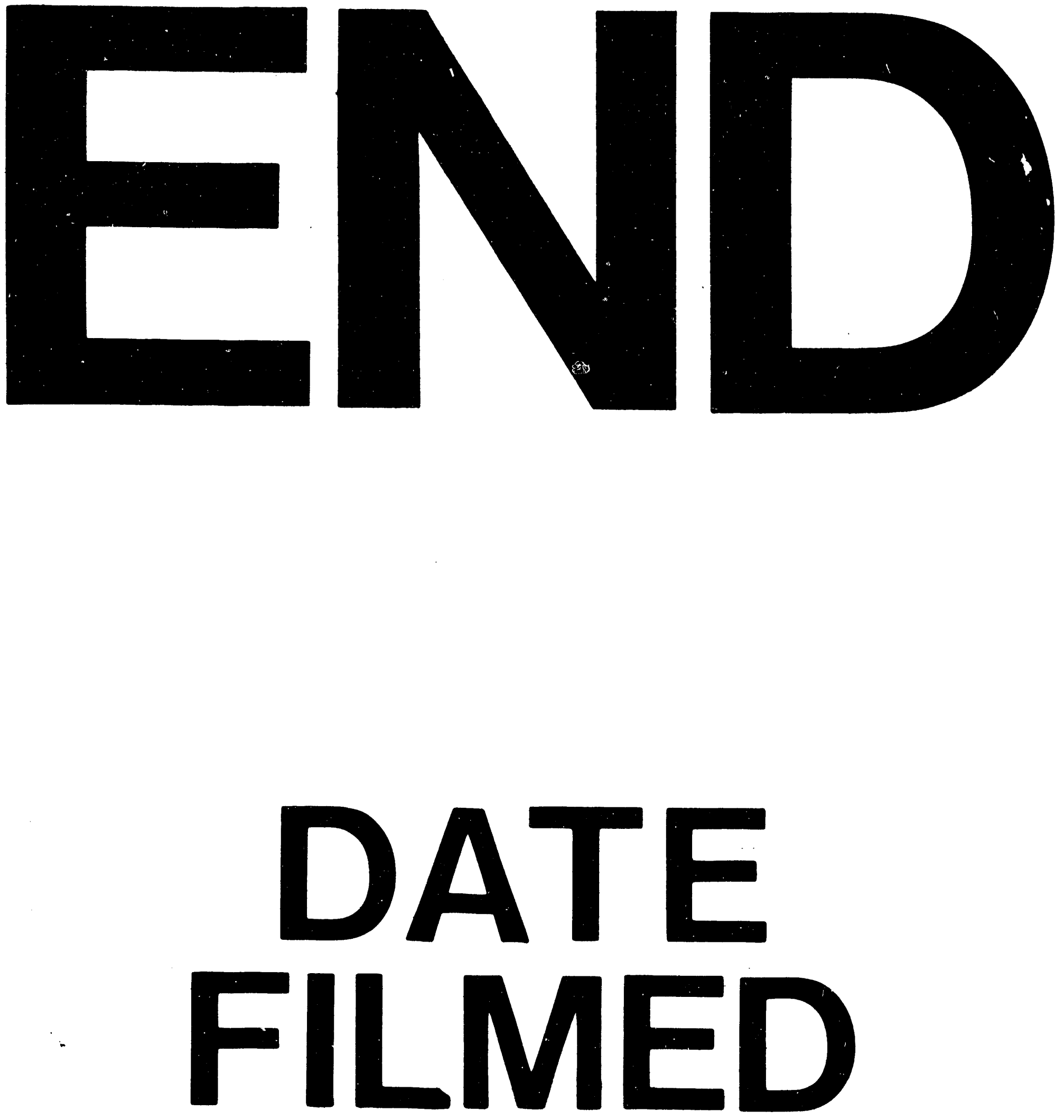

1

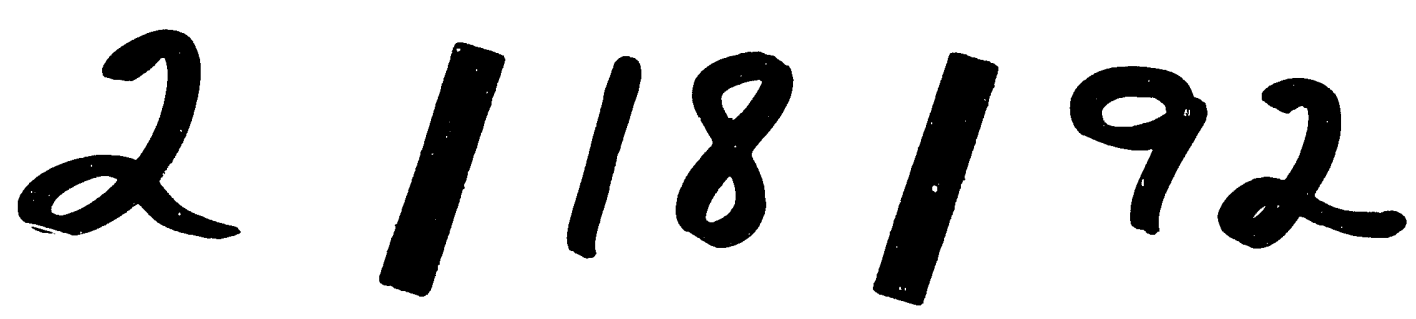


